\title{
MOTIVOS DE UM INDIVÍDUO PARA PRATICAR ATIVIDADES FÍSICO-ESPORTIVAS
}

\author{
Carlos Alberto de Andrade Coelho Filho' \\ Universidade Federal de Juiz de Fora, Juiz de Fora-MG, Brasil \\ Regina Glória Nunes Andrade \\ Universidade do Estado Rio de Janeiro, Rio de Janeiro-RJ, Brasil
}

\begin{abstract}
RESUMO. Este estudo objetiva investigar os motivos de um indivíduo para aderir à prática regular de atividades físicoesportivas. É um estudo de caso qualitativo que emerge do interesse pelos aspectos intrínsecos de um caso particular. $\mathrm{O}$ instrumento utilizado para coleta de dados foi a entrevista. Tendo em vista a análise e a interpretação dos dados coletados, concluímos que: (1) a prática de atividades físico-esportivas pode estar associada a motivos que não são representados, isto é, a impulsos que permanecem obscuros; (2) o sujeito pratica regularmente atividades físico-esportivas porque com ela se sente mais consciente dos seus limites, de sua potência e de sua estética; (3) sua prática regular está associada à identificação com atividades físico-esportivas variadas; (4) o sujeito pratica-as regularmente, porque associa essa prática a um remédio saudável, porque mexer com o corpo é brincar com o corpo; (5) o sujeito pratica regularmente atividades físicoesportivas porque as qualidades da imaginação o confortam e a ilusão o acolhe e o move.
\end{abstract}

Palavras-chave: Exercício; motivação; imaginário.

\section{REASONS FOR AN INDIVIDUAL TO PRACTICE PHYSICAL SPORTS ACTIVITIES}

\begin{abstract}
This study aims to investigate the reasons why an individual joins regular physical sports activities. This is a qualitative case study which rises from the interest in inherent aspects of a specific situation. The instrument used for data collection was an interview. Considering the analysis and interpretation of the collected data, we have concluded that: (1) the practice of physical sports activities may be associated with reasons which are not shown, that is, with impulses which remain unclear; (2) the individual practices physical sports activities regularly, because by doing so they feel more aware of their limits, their power, their aesthetics; (3) the regular practice of such activities is associated with the identification with varied physical sports activities; (4) the subject practices such activities regularly, as this practice is associated with a healthy medication, since moving the body means playing with the body; (5) the individual practices physical sports activities regularly because the qualities of the imagination are comforting to them, the illusion shelters him and makes him move forward.
\end{abstract}

Key words: Exercising; motivation; imagery.

\section{MOTIVOS DE UN INDIVIDUO PARA LA PRÁCTICA DE ACTIVIDADES FÍSICO-DEPORTIVAS}

RESUMEN. Este estudio tiene el objetivo de investigar los motivos de la adhesión de un individuo a la práctica regular de actividades físico-deportivas. Se trata de un estudio de caso cualitativo que emerge del interés por aspectos intrínsecos de un caso particular. El instrumento utilizado para la recolección de datos fue la entrevista. Teniendo en cuenta el análisis y la interpretación de los datos recogidos, concluimos que: (1) la práctica de actividades físico-deportivas puede estar asociada a motivos que no son representados, esto es, a impulsos que permanecen oscuros; (2) el sujeto practica regularmente actividades físico-deportivas, porque, así, se siente más consciente de sus límites, de su potencia, de su estética; (3) su práctica regular está asociada a la identificación con actividades físico-deportivas variadas; (4) el sujeto las practica regularmente, porque asocia esa práctica a un remedio saludable, porque moverse con el cuerpo es jugar con el cuerpo; (5) el sujeto practica regularmente actividades físico-deportivas porque las cualidades de la imaginación lo confortan, la ilusión lo acoge y lo mueve.

Palabras-clave: Ejercicio; motivación; imaginario.

1 Endereço para correspondência: Faculdade de Educação Física e Desportos, Campus Universitário S/N, São Pedro, CEP 36036-900 - Juiz de Fora-MG, Brasil. E-mail: carlos.coelho@ufjf.edu.br 
Em vários países se tem documentado uma diminuição preocupante do nível de atividade física da população (Organización Panamericana de la Salud, 2006). Muitas pessoas iniciam a prática de exercícios físicos estimuladas por várias razões, mas não conseguem incorporá-la em seu cotidiano, deixando-a de lado na maioria das vezes (Santos \& Knijnik, 2006).

Estudos que se dedicam a investigar os motivos que contribuem para a adoção de comportamentos fisicamente ativos seguem, em geral, referenciais teórico-metodológicos provenientes das ciências biomédicas (Castro, Miranda, Silva, Palma, \& Resende, 2009), avaliando dados quantitativos insuficientes para dar conta da complexidade das variáveis relacionadas ao problema da adesão a hábitos de prática de atividades físicas, porquanto a regularidade de um comportamento e a transformação desse comportamento em hábito envolvem múltiplas questões (Moretti, Almeida, Westphal, \& Bógus, 2009). Infelizmente, sobre este assunto, evidencia-se a carência de estudos que deixem de procurar respostas nas superfícies expostas dos fenômenos e mergulhem nas suas profundezas (Palma, 2009).

Coelho Filho (2007) observa que para a prática regular de atividades físico-esportivas é preciso desejo e satisfação de necessidade psíquica. Pergunta o autor: "Qual é o segredo desse enigma? Por que muitas vezes o sujeito deseja, mas na prática não adquire esse comportamento? A determinação, seja ela 'positiva' ou 'negativa', vem de onde?". Nesse sentido, nossa questão se coloca entre os elementos de uma determinação "positiva", introduzida nas realidades psíquicas, e os de uma definição relativista, objetiva (Lacan, 1998).

Assumir a posição de se impor o desafio de enfrentar o problema acima delineado é, em certo sentido, focalizar um fenômeno psicossocial complexo que justifica o esforço de compreensão. O objetivo desta pesquisa é investigar os motivos da adesão à prática regular de atividades físico-esportivas. Adotamos neste trabalho o uso do termo atividade físico-esportiva por dois motivos: (1) porque o que nos interessa é uma aproximação das práticas corporais que se tornaram tradicionais no campo da educação física, como as ginásticas, os esportes, os jogos, as danças (Vago, 2009); (2) porque constatamos que o termo tem sido utilizado na literatura científica para caracterizar estas práticas corporais (cf. Molina \& Beltrán, 2007).

\section{MÉTODO}

Esta pesquisa baseia-se em um caso de adesão à prática regular de atividades físicoesportivas, especialmente, associado à história de vida de um indivíduo. Podemos caracterizá-la como um "estudo de caso qualitativo" que emerge do interesse pelos aspectos intrínsecos de um caso particular (Alves-Mazzotti, 2006). Pretendemos levar os leitores a estabelecer relações entre o que foi apreendido do caso (com sua história, única) e os acontecimentos vividos por eles próprios em outros contextos e/ou situações. Sobre isto assim se expressa Alves-Manzotti (2006, p. 647):

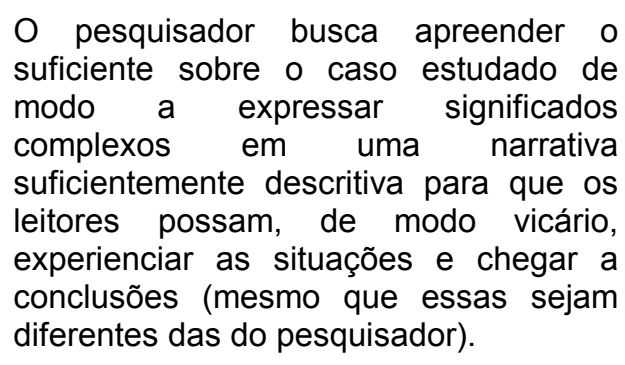

O instrumento utilizado para coleta de dados foi a entrevista, gravada e transcrita, para outro estudo, de modo que a análise aqui desenvolvida apoia-se em estudo já divulgado (Coelho Filho, 2007). Trata-se do depoimento de um senhor de 59 anos de idade, engenheiro de profissão, nascido e residente na cidade do Rio de Janeiro. Como podemos observar no trecho a seguir, é uma vida que está sendo vivida, pela prática de atividades físico-esportivas, no emaranhado das relações sociais:

Rapaz, hoje isso aí eu não largo de jeito
nenhum. Só aqui na academia eu vou
para... A academia tem 25 anos; eu
tenho 23 anos de academia. Veja bem:
tem cara que tem 23 anos; fica um mês
sem vir, dois meses. Eu, sem férias, não
tirei férias da academia, direto.

O critério de escolha para participar deste estudo foi a admiração pela prática da atividade físico-esportiva, e está ancorado em uma personagem. Ao longo dos nossos (primeiro autor desta pesquisa) anos de trabalho na academia de ginástica por ele citada, já que lá 
atuamos profissionalmente durante mais de uma década, esse senhor, amistosamente, nas brincadeiras com o proprietário da instituição e com alguns colegas, representa uma personagem, o $n^{\circ} \mathrm{Um}$. No extrato acima em destaque, o entrevistado fornece pistas para que possamos compreender a designação de $n^{\circ} U m$. Nos 25 anos de existência dessa academia de ginástica, situada no Município do Rio de Janeiro, mesmo que outros "alunos" (praticantes de exercícios físicos na instituição), durante as brincadeiras, baseando-se no critério de antiguidade, reivindiquem para si a "honra" de ser $n^{\circ} U m$, é ele quem a merece, pois, como diz, foi quem não tirou "férias". Pudemos constatar em nossas observações que o $n^{\circ} U m$ não deixa de estar presente um só dia na academia, quase sempre pela manhã, com o raiar do sol, diferentemente dos outros (poucos, é certo) que, apesar de terem "23 anos" como ele, ficam "um mês sem vir, dois meses", e, quando aparecem, curiosamente, preferem muitas vezes a sauna em vez do exercício físico, mesmo com o forte calor que é costumeiro na região. À admiração constatada no senhor de 59 anos de idade pela prática da atividade físico-esportiva soma-se a personagem, o $n^{\circ} U m$, justificando a peculiaridade/singularidade do caso, que vai permitir aprofundar o necessário conhecimento sobre a temática.

As questões mais gerais que nortearam as reflexões na entrevista foram: (1) Quais as atividades físico-esportivas que você praticou ao longo da vida? (2) Quais os fatores motivacionais que o levaram a essas práticas? (3) Qual a relação que você pode estabelecer entre essas práticas e $\mathrm{O}$ seu amadurecimento biopsicossocial? (4) Quais os resultados (bônus ou ônus) que essas práticas the proporcionaram? (5) Qual era/é a regularidade dessas práticas e o tempo diário destinado a elas? (6) Quais as atividades físico-esportivas que você pratica atualmente e suas respectivas motivações? (7) Se um filho ou neto lhe pedisse uma orientação de como manter a regularidade da prática físico-esportiva, o que diria?

Como referencial teórico para a análise dos dados oriundos das mensagens transcritas, isto é, provenientes da entrevista, utilizamos a "análise de conteúdo" (Bardin, 1977). Após a leitura (atenta, crítica, aberta a diferentes ideias e contribuições) desse material, foi possível captar e compreender ao menos um sentido das comunicações, mas também e principalmente desviar o olhar para outras significações. Neste sentido, diz-se que o interesse da análise não reside na descrição dos conteúdos, e sim, no que estes poderão ensinar após serem tratados relativamente a "outras coisas" (Bardin, 1977).

\section{RESULTADOS E DISCUSSÃO}

A história do sujeito que reencontra algo com a prática da atividade físico-esportiva antecede à do $n^{\circ} U m$. Se hoje não abdica do movimento, foi somente num pequeno período, no início do seu casamento, que ficou "só pela casa, mais ou menos um ano parado, jogando pelada uma vez ou outra". Esse tempo relativamente inativo pode ter sido desgastante para o jovem, que sempre gostou de esporte, como nos mostra o diálogo a seguir:

\author{
Servi na paraquedista. Logo depois, \\ jogava futebol" \\ - Jogava futebol por lazer? \\ É, lazer, lazer. Treinei boxe; mas isso lá \\ com uns 17, 18 anos, antes de ir para \\ paraquedista.
}

- E antes disso?

Aí eram aquelas peladas de rua que todo mundo faz.

- E a Educação Física na escola?

Educação Física... Sempre gostei, sempre gostei.

Uma história corriqueira, como a de tantos jovens que se identificam com a prática esportiva e que, no seu espectro, vislumbram caminhar, reencontrar vida no movimento. Realmente, antes da engenharia, o rapaz investiu no paraquedismo: "Eu tinha uma motivação, eu gostava, eu achava que o que eu queria era ser paraquedista." Ele acreditava no caminho a seguir; mas, e essa crença, como se constituiu? Se pensarmos na voz (como pulsão) que determina o destino, interessantes se fazem os motivos que não são representados, isto é, os impulsos que permanecem obscuros. Isso porque, para o jovem rapaz que vislumbrou o paraquedismo como horizonte, não foi importante representar e avaliar o lugar a partir do qual algo começou a se fazer presente (Bhabha, 1998), e sim, satisfazer a necessidade psíquica (o desejo de ser paraquedista). O entrevistado faz então um exercício de análise, 
tenta recuperar aquilo que foi irrelevante para ele no passado: "Então, uma motivação natural. Talvez até influenciado por amigos, por conhecidos." Naquele momento, portanto, a natureza da motivação do jovem que queria ser paraquedista estava ancorada, também, no grupo de ocasião, além de - é claro -, nas marcas ou "malhas" que essa natureza já antes angariara. Como nos lembram Queiroz e Otta (2000), parece imperioso alterar o corpo humano segundo padrões culturalmente estabelecidos, para afirmação de uma identidade grupal específica.

O corpo reage aos estímulos e estes lhe deixam marcas - por exemplo, influências que refletem a "nossa consciência", como diz o entrevistado: "... eu achava que o que eu queria era ser paraquedista". Certas ordens de motivações então transitaram pelo corpo do jovem que queria ser paraquedista, e que o foi não sem dor, não sem vontade e com uma boa dose de trabalho negligente, se assim o considerarmos:

Paraquedista, tem horas que até você se arrepende de ter entrado para lá, porque, "nego", te pega firme, rapaz. Para tu ter uma ideia: num curso de paraquedismo, na minha época, que era um negócio muito pesado, em 64, entram 250 homens, saem paraquedistas 80, 70 . Entendeu? Porque é uma atividade física muito intensa. Acredito até que sem um pouco de critério, porque o que você mais "paga" lá é "canguru".

O sacrifício do aspirante a paraquedista, que em certos momentos até "se arrepende de ter entrado lá", será recompensado e deixará marcas, evidentemente, também, no $n^{\circ} U m$. O jovem que se aventura em práticas esportivas de risco vence desafios, supera obstáculos e renasce vitorioso (Costa, 2000); mas muitos ficam pelo caminho, não conseguem ultrapassar os rigores do treinamento, o medo da "queda", a frustração, a dor. Como diz o entrevistado: "Para tu ter uma ideia: num curso de paraquedismo, na minha época, que era um negócio muito pesado, em 64, entram 250 homens, saem paraquedistas 80, 70. Entendeu?"

2 No contexto discursivo em questão, "pagar" significa repetir a atividade com muita frequência. Já no movimento denominado de "canguru", o praticante executa seguidos saltos com os joelhos fletidos, o que pode causar danos a essa articulação.
Assim, é em meio a um emaranhado de possibilidades, pensamentos e sensações representadas ou não - que o corpo se move: avança, recua. Imaginemos, então, num pequeno deslocamento temporal e qualitativo, o jovem engenheiro recém-casado que guarda o paraquedista de ontem e projeta o $n^{\circ} U m$ de amanhã: são identidades que se abrigam no corpo, transformações que se concretizam em suas especificidades, dadas as condições sóciohistóricas e ideológicas. Como observa Ciampa (2001), o humano é uma porta abrindo-se em muitas saídas; identidade humana é vida que se renova no cotidiano, a cada reencontro; e ainda, identidade é metamorfose.

O contexto imediato é o da entrevista com o engenheiro de 59 anos, apaixonado por exercícios físicos. O contexto amplo traz para consideração elementos que derivam da forma como a sociedade se organiza, com as suas instituições, entre elas a família (o casamento) e o trabalho, no modo como distribui o poder, com as posições de mando e obediência (Foucault, 1996). Nesse sentido, o jovem recém-casado pode ter sentido os efeitos da repressão quando ficou "só pela casa, mais ou menos um ano parado, jogando pelada uma vez ou outra". No arroubo de liberdade, guardando em si o imaginário de conquista e prazer com a prática da atividade físico-esportiva, busca a academia de ginástica, em que vai nos contemplar com a vida do $n^{\circ} \mathrm{Um}$. Embora o contexto imediato do depoimento não nos forneça explicitamente essa interpretação, é o trabalho do engenheiro, no interior de uma instituição, que explica a história de alguém que se sente sujeito da própria vida:

Vou te dar um exemplo que vai matar isso tudo. Eu trabalhei numa firma durante 35 anos, pedi demissão. Pedi demissão por quê? Acharam que eu estava maluco: "Como é que você larga um salário razoavelmente bom, sem motivo nenhum, conceituado dentro da empresa?" Que o presidente veio pedir para eu ficar, e eu não quis ficar. Porque mudou a direção da empresa e de repente comecei a ser muito solicitado. Reunião às 10 horas da manhã; quando era 2 horas da tarde eu estava na padaria comendo sanduíche. Não dá. Reunião 6 horas da tarde, chegava em casa às 10! Aí eu comecei a me questionar: "ninguém tem o direito de me transformar num cara obeso, estressado, com colesterol alto". Saí da empresa tem uns dois anos. Logo depois, fui almoçar 
com um pessoal lá na empresa. Batendo papo, aquele negócio todo, eu falei: "Rapaz, sabe que eu estou arrependido?" Aí, os caras: "Se arrependeu?" "De não ter saído antes!" Mudou completamente. É evidente que eu já tinha uma empresa. Então, hoje eu estou lá. Apenas saí de uma cadeira e sentei em outra cadeira. Toco hoje a minha empresa, quando meu filho antes tocava para mim, junto com o meu sócio. Primeira decisão minha dentro da empresa: comprar uma mesa de reunião. Porque naquele momento eu pensei: "Quem vai marcar reunião aqui sou eu". Eu sou o dono, entendeu? Passei a marcar reunião. A minha reunião é às 10 horas da manhã, depois vamos almoçar; eu, o sócio, meu filho, o pessoal. Bate-se um papo, um outro esquema. Por que às 10 horas? Porque se o cara não tiver aquele compromisso... Dá tempo dele ir a sua academia. Todo mundo lá pratica, na minha empresa. Todos têm um astral muito bom.

Alternativas de interpretação entrecruzam-se nos acontecimentos que se multiplicam no discurso acima. A mudança de rumo, apesar de considerada tardia, representa uma vida nova que passa a ser vivida - como diz o entrevistado: "um outro esquema". O lugar ocupado pelo empregado - bem remunerado, mas oprimido, descompensado -, fica vazio. Talvez tenha sido preenchido por outro trabalhador, e certamente o foi, mas isso a história não conta. O que conta é a cadeira do patrão (ou a voz) que passa a ocupar o sujeito - um espaço sensível que, no discurso, deixar transparecer o indivíduo que não tem o direito de transformar o outro "num cara obeso, estressado, com colesterol alto". Por isso, além da preocupação com a alimentação adequada e com o bate-papo afetivo, a prática regular do exercício físico é valorizada na empresa. E assim, "todos têm um astral muito bom".

Por outro lado, queremos registrar também a ideia de compromisso ("Porque se o cara não tiver aquele compromisso..."), que nos remete para ônus psíquico, acordar cedo, "malhar". Nem todos se sentem dispostos a assumir "o" compromisso, bastando os que a vida já lhes impôs ao longo do tempo, ou ainda impõe. Assim, sobretudo quando a experiência (a memória) da atividade físico-esportiva não é satisfatória, o cansaço mental e os subterfúgios podem se manifestar (Coelho Filho, 2007). Não deixemos de observar, também, que a repressão pode advir do próprio contexto que a subjuga, na medida em que vai induzir no sujeito "o" compromisso: "Todo mundo lá pratica, na minha empresa. Todos têm um astral muito bom".

Vamos nos deter agora na potência interior que se mostra necessária para o movimento de ruptura com as instituições que mantêm o sujeito sob tutela (a família, o trabalho, a publicidade), as que exercem autoridade sobre seu livrearbítrio. Em outras palavras, reconhecemos a consciência que determina o conflito psíquico e podemos nos posicionar. O $n^{\circ} \mathrm{Um}$ reflete: "Acho que isso é uma coisa que vai se acumulando, vai somando. Vai somando até chegar a um ponto ideal". Percebe-se que o entrevistado representa um processo cumulativo, de maturação e metamorfose psíquica, que culmina com a possibilidade de avaliação, posicionamento e poder de decisão. Essa questão da escolha é sempre difícil, e é tanto mais tranquila quanto mais consciente for o sujeito quanto aos seus limites, sua potência e sua estética.

O entrevistado remete para a prática da atividade físico-esportiva como um remédio saudável:

\begin{abstract}
É um remédio, atividade física é remédio. É um remédio bom. Por quê? Eu outro dia li o artigo de um médico; ele falando exatamente isso, que as pessoas tomam muito remédio, sem a mínima necessidade. Não é necessidade do cara ter o colesterol alto, de repente ele pode controlar esse colesterol com atividade física. A glicose, por exemplo: eu fatalmente seria diabético. Fatalmente! Meu pai era diabético. Eu posso te garantir que eu só não sou diabético porque eu faço muita atividade física.
\end{abstract}

Assim, a interpretação se impõe. Como a autoestima depende intimamente da libido narcisista (Freud, 1914/1974), é no seio do narcisismo humano que o $n^{\circ} \mathrm{Um}$ conclui seu aprendizado, no gostar de si, na atitude de autoestima madura. O tempo o faz entender a vida de outro modo:

Numa determinada época da tua vida você está muito ligado à vaidade, procurar um corpo melhor. Depois, com o tempo, isso vai desaparecendo, vai se transformando em outra coisa. Você começa a se preocupar mais com a saúde. Passa a se preocupar mais com 
o teu colesterol, com os teus triglicerídeos. Então, acho que isso não deixa de ser um amadurecimento.

Ele realmente tem consciência dos benefícios que a prática da atividade físicoesportiva Ihe proporcionou ao longo do tempo, e continua a proporcionar. Também tem consciência do controle corporal e da metamorfose: de um lado, o equilíbrio estético; do outro, a força para a transformação permanente. Por isso, afirma:

Eu acho que só teve bônus. Por exemplo, há trinta anos meu peso varia de 75 a 76 quilos. Quer coisa melhor do que isso? Acho que só tem bônus... Eu me acho mais confiante, com poder de decisão maior, sem receio de nada. Eu acho que isso te dá muito...

Sorte do $n^{\circ} U m$, que "sobreviveu" aos rigores (intensidade) do treinamento (para paraquedista). Assim, a manutenção do peso corporal (no que esse peso possa ser interpretado como medida subjetiva quantitativa e qualitativa, como moeda de circulação pelo labirinto da vida ${ }^{3}$, como consciência corporal) e o poder de decisão se conjugam com outras benesses. Estas, nós as veremos logo abaixo. Mas importa ainda, à frente, reafirmar a regularidade e destacar que o tempo destinado ao exercício físico é o do início da manhã, antes do trabalho, ou mesmo nos feriados e nos finais de semana: "Sempre foi regular. Esse tempo diário, sempre a mesma coisa, mas só com frequência diária. Por exemplo, se o mês tem trinta dias, pelo menos vinte e oito dias eu faço atividade física." Registrem-se aqui a vontade e a regularidade. Os motivos, como vimos, podem ser variados nas interpretações, nas vozes como pulsão, e certamente envolvem o campo do imaginário, o repouso e o movimento do "herói".

Bachelard (2001) situa-nos entre as imagens do repouso e do movimento. $O$ autor estuda as grandes imagens do refúgio (repouso): a casa, o ventre, a gruta. As reflexões de Bachelard partem do que denomina de "lei da isomorfia das imagens da profundidade". Ele diz que um psicanalista não terá dificuldade em provar que essa isomorfia provém de uma mesma tendência

3 A imagem do labirindo como metáfora do caminho que percorremos em nossa existência, pode ser de prazer ou de desprazer, de felicidade, mas também de catástrofe (Feitosa, 2002). inconsciente: a volta à mãe; mas acrescenta em seguida: "tal diagnóstico prejudica o valor próprio das imagens" (Bachelard, 2001, p. 11). A crítica de Bachelard segue no sentido de não nos fixarmos simplesmente nessa volta à mãe, mas de podermos estudar os itinerários desse retorno. Não é reduzindo o psiquismo a suas tendências profundas - diz Bachelard - que se explicará seu desenvolvimento em imagens múltiplas, superabundantes, sempre renovadas. A agitação (ou o movimento), por seu turno, é estudada por Bachelard com a insígnia do labirinto. Para Bachelard, diferentemente da gruta, no labirinto nós seguimos sonhos mais tumultuosos, mais tortuosos, menos tranquilos, provindos de uma camada inconsciente mais profunda, que dialetiza o sonho dos refúgios mais espaçosos. "Sob muitos aspectos os sonhos da gruta e os do labirinto são contrários. A gruta é um repouso. O labirinto repõe o sonhador em movimento" (Bachelard, 2001, p. 11).

É precisamente por essas imagens múltiplas, superabundantes, que estamos agora interessados. A relação com a falibilidade do corpo (na "intimidade do conflito"), por exemplo, que dialetiza o repouso e o movimento, pode ser realçada nessa nossa história. Interpretamos que com a prática da atividade físico-esportiva o $n^{\circ}$ Um reencontra o repouso, o "afago materno", quando não falta à academia de ginástica, se não fica "com dor na consciência". Essa dor tortuosa, vinculada à falibilidade do corpo e manifestada em contraponto à potência erótica latente de "sua majestade, o bebê" (Freud, 1914/1974), torna a pô-lo em movimento: de um lado, porque "há trinta anos a prática da atividade física faz com que seu peso varie de 75 a 76 quilos", do outro, porque com essa prática ele se acha "mais confiante, com poder de decisão maior, sem receio de nada". E pergunta: "Quer coisa melhor do que isso?" Ele pode então arriscar, ousar novos caminhos (profissionais, por exemplo) de cabeça erguida, confiante, com a calma cotidiana da conquista "heroica".

Mas o "outro" da identificação, nesse caso, nos parece mais difuso, menos localizável do que 0 paraquedista com que 0 jovem se identificou no passado. Ele se situa - digamos mais próximo do "altivo e longínquo castelo interior" (Lacan, 1998, p. 101); contudo, para o entrevistado, a "intimidade do conflito" é facilmente percebida: 


\begin{abstract}
Se você cuidar do corpo, automaticamente a sua parte psicológica melhora bastante. Porque uma coisa é você se olhar no espelho e se sentir satisfeito. Se você está satisfeito com a sua barriga, você acha a sua barriga bonita, a sua parte psicológica está legal. Mas se você olha no espelho e acha a sua barriga: "pô, está feia, você está com o corpo horroroso!" Aquilo também não vai ser bom para a sua parte psicológica.
\end{abstract}

$\mathrm{O} n^{\circ} \mathrm{Um}$ supera-se, sai em busca do melhor estado psicológico. As qualidades da imaginação o confortam, a ilusão o acolhe e o recoloca em movimento. "O sonhador não consegue sonhar diante de um espelho que não seja profundo", diz Bachelard (2001, p. 157). O corpo que se mantém harmonioso, em certo sentido, com a "barriga do corpo de jovem", ou com o "peso do corpo de jovem", é um modelo de corpo; ou seja, em nossos corpos, uma quantidade de gordura ousadamente saliente, por exemplo, sobranceia o "duplo" e indica uma profundidade correspondente de pensamento, e assim,

\begin{abstract}
... a imagem especular parece ser 0 limiar do mundo visível, a nos fiarmos na disposição especular apresentada na alucinação e no sonho pela imago do corpo próprio, quer se trate de seus traços individuais, quer de suas faltas de firmeza ou suas projeções objetais, ou ao observarmos o papel do aparelho especular nas aparições do duplo em que se manifestam realidades psíquicas de outro modo heterogêneas (Lacan, 1998, p 98).
\end{abstract}

\section{Acrescenta o entrevistado:}

O espelho é o seu melhor amigo. Por que o espelho é o seu melhor amigo? Porque ele te acompanha, ele vai acompanhando o seu envelhecimento. $E$ você está olhando para o espelho, está olhando para você todo dia, você acha que está sempre a mesma coisa. Apaga isso que eu falei e faz o seguinte. Aos oito anos você se olha no espelho e depois vá se olhar aos cinquenta. Dá um tiro na cabeça, entendeu? Porque o espelho não deixa você ver a sua transformação. A sua transformação é diária, que você não percebe. Não é?

Se estudarmos as nossas imagens materiais, descobriremos - enunciando como psicanalistas e parafraseando Bachelard - a "imago" de nossa energia. Em outras palavras, "a matéria é nosso espelho energético; é um espelho que focaliza as nossas potências iluminando-as com alegrias imaginárias" (Bachelard, 2001, p. 20). O que é por nós estudada é a matéria imaginada, que situa a instância do "eu". Os devaneios materiais, como nos mostra Bachelard, mudam a dimensão de nossas potências; "dão-nos as ilusões da onipotência. Essas ilusões são úteis, pois já são um encorajamento para atacar a matéria em seu âmago" (Bachelard, 2001, p. 20). No caso do $n^{\circ}$ Um, a matéria a ser atacada, o corpo próprio, é renovada com a prática da atividade físicoesportiva. O movimento proporciona-lhe a alegria imaginada da não transformação, o repouso no "berço materno" e a potência.

Importa notar, contudo, que nos encontramos no campo da relação especular, com o $n^{\circ} \mathrm{Um}$ diante do espelho. "O espelho é o seu melhor amigo", porque ele se identifica com a imagem ideal de saúde e beleza. $\mathrm{Na}$ profundidade de pensamento, o "herói" repousa nessa imagem. No exemplo que evocamos do $n^{\circ}$ $U m$, a questão não é, simplesmente, a forma superficial do corpo no espelho, mas a colocação do indivíduo ao alcance do campo de reflexão de um espelho. Como observa Bachelard (2001), "um materialismo externo mascara o materialismo profundo, o materialismo do sonhador" (p. 117). A questão se desdobra, então, porque o materialismo do sonhador, no sentido em que o interpretamos, é determinado pelo meio. Cria-se uma obrigação que, na "intimidade do conflito", pode transformar-se num hábito. Essa jornada também é "heroica", mas gratificante; mas para percorrer esse labirinto, segundo o entrevistado, é preciso ir "bem devagar":

Sem obrigação: "pô, vou correr todo dia!" Sem isso, devagar, sem pressa, até pegar esse hábito. Depois que você consegue se habituar a determinadas coisas, você faz toda a vida. Eu acho que não tem ninguém que entre para uma academia, que no primeiro mês ele não tenha vontade de desistir. Basta ver a própria academia, é uma rotatividade violenta.

Por outro lado, paradoxalmente, ele afirma: "Eu acho que é uma obrigação de cada um cuidar de si. O cara não cuida do carro? Fica lá lavando o carro, tem cuidado. Esse mesmo 
cuidado ele tem que ter com o corpo." É, ainda, na vitória pelo cumprimento da obrigação cotidiana, na conquista do cuidado de si (Foucault, 1985), que o espelho focaliza as potências do "herói", iluminando-as com alegrias imaginárias.

Vale observar que a alegria imaginária é também refletida no entorno do hábito, nos espaços que o $n^{\circ}$ Um ocupa. Os espaços contribuem para o hábito, para a regularidade: contato com a "natureza urbana", com as pessoas, nos ambientes fechados, nas florestas citadinas, nas praias:

Tenho que variar, até para não enjoar. Por exemplo, não vou fazer "spinning" todo dia. Vai ter uma hora que você vai enjoar. Então eu venho caminhando hoje. Hoje é totalmente diferente. Eu revejo uma árvore que tu nunca viu. De repente passa despercebido. Você de carro não vê. Você caminhando: "pô, não tinha reparado isso, que árvore bonita!" Então você vem. Isso te motiva também. Às vezes você está cheio de caminhar na praia, pego um amigo e vou lá para o Alto da Boa Vista, lá para as Paineiras. É outro lance.

A criatividade corporal é destacada pelo $n^{\circ}$ Um juntamente com a leveza, a espontaneidade. $O$ fato de se identificar com práticas diferentes contribui para a sua regularidade:

Eu acho que ninguém consegue fazer a mesma coisa todo dia. Se você fizer uma coisa todo dia, todo dia, eu acho que pinta alguma coisa de anormalidade na cabeça do cara. Ele passa a ser um robô, não sabe nem o que está fazendo. Acho que isso não tem que ser um negócio automático, tem que ser muito espontâneo. Até para ter um resultado melhor.

Por um lado, então, lembremo-nos da observação de Freud de que várias identificações podem coexistir. Isto acontece quando o conjunto das identificações de um indivíduo forma uma espécie de sistema relacional. Dito em outras palavras, o "supereu" é constituído por identificações com ideais culturais não necessariamente harmonizados entre si (Laplanche \& Pontalis, 1970), mas ainda assim é fonte de criatividade, como bem situa o entrevistado. Por outro lado, Lacan coloca a identificação como base da identidade
(Roudinesco \& Plon, 1998). Interpretamos que a identificação imaginária dá-se com a figura do "herói". É a identidade da personagem, o $n^{\circ} \mathrm{Um}$, o "herói", que supera obstáculos na vida cotidiana, que cria possibilidades, que transita com maestria pela "intimidade do conflito". Ademais, lembremo-nos: é sobre as imagens múltiplas, superabundantes, que estamos debruçados - em certo sentido, pela "mimicry das fantasias do herói” (Costa, 2000, p. 201). É o entorno o que determina. $\mathrm{O} n^{\circ} \mathrm{Um}$, por exemplo, vive a estética de caminhar na praia:

\begin{abstract}
As coisas que estão em sua volta, claro que te motivam. Isso também te leva a fazer, ir para a praia caminhar. Você imagina uma praia deserta: na primeira caminhada você vai ficar apreciando o mar, na segunda também; mas aquilo chega uma época que vai saturando. $\mathrm{Na}$ academia também. Se você vê a sua academia, que só tem aqueles ferros, você ficar ali, você não consegue fazer. Sempre tem alguma coisa para te motivar. Não é isso? Andar pela areia... areia. Não tem nada mais que te motive a andar pela areia? Apreciar. Você às vezes olha na tua frente, você olha e vê uma imagem, uma coisa qualquer que você vai chegar. Tem aquela motivação de chegar próximo para apreciar melhor. Não é?
\end{abstract}

É o "reencontro do algo melhor" (Coelho Filho, 2007), com a caminhada na praia, ligada a uma função de falta, que, neste momento, podemos situar a partir do "estádio do espelho" (Lacan, 1998). Antes, retomemos a interpretação que fizemos do $n^{\circ} \mathrm{Um}$, quando enfatizamos o repouso e o movimento: ele pode arriscar, ousar em novos caminhos de cabeça erguida, confiante, com a calma da conquista "heroica". Mas, tendo em mente a função de falta: primeiro, é um engodo supor uma harmonia ou uma calma que muitos fatos da etologia animal contradizem; segundo, não devemos mascarar a contundência de uma função de falta com a questão do lugar que ela pode assumir numa cadeia causal (Lacan, 1998). "As coisas que estão em sua volta, claro que te motivam", afirma o $n^{\circ} \mathrm{Um}$. Assim é que, "longe de pensarmos em eliminá-la, essa função parece-nos, agora, ser a origem mesma da noese causalista, a ponto de confundi-la com sua passagem ao real" (Lacan, 1998, p. 74); ou seja, o real é o "corpo despedaçado", é a falibilidade do corpo. 
Contudo, na dialética do repouso e do movimento, o que se manifesta é a alegria imaginada da "não transformação", o repouso no "berço materno". Além disso, observemos que essa função é de uma falta mais crítica, pois, como nos alerta Lacan, seu encobrimento é o segredo da jubilação do sujeito.

Neste ponto, uma questão nos soa pertinente: qual a unidade ideal, qual a "imago salutar" que o $n^{\circ} \mathrm{Um}$ projeta de si mesmo no momento em que "olha à frente e vê uma imagem, uma coisa qualquer que você vai chegar"? Consideremos a interpretação de que o desejo (silencioso, inconsciente) brota no emaranhado das relações do corpo que vê com o corpo que é visto, e avancemos um passo no campo do jogo.

Numa aproximação superficial, podemos pensar no sentido do jogo, segundo Buytendijk (1977), como uma forma de distração, que tradicionalmente se forma na sociedade para resolver de maneira inofensiva a gravidade dos impulsos infantis de prestígio, aventura, competição e sucesso. Além disso, como diz o autor, os jogos muitas vezes significam exercícios físicos, que podem ser meios adequados para o sujeito se sentir fisicamente disposto e forte. O jogo humano, porém, apresenta ainda muitos outros aspectos. Ainda conforme Buytendijk (1977), quanto mais detalhadamente se estuda o comportamento animal, mais convincente se torna a sua relação com um tipo de compreensão degradada, fechada, vivida "corporalmente" - portanto, carnal - das relações de sentido. Por isso é necessário, "para um conhecimento da essência do jogo humano ter sempre em vista a importância fundamental dos conceitos 'corps sujet' (subjetividade corporal) e 'corps connaissant' (corpo como consciência)" (Buytendijk, 1977, p. 66). Todo jogo humano é, de algum modo, relacionado com o fundamento irracional e obscuro dos nossos instintos e paixões, capacidades, disposições, condições e estados de ânimo, e com o também inteiramente inexplicável elemento criador em cada atividade. Quando mexemos o corpo, por exemplo, produzimos, a partir de um impulso de tensão, uma aparência que, pelo olhar e pela própria percepção, volta para nós, estimulando nova tensão. Mexer com o corpo é brincar com o corpo, que brinca conosco. Assim, como ensina Gadamer (2011), "o atrativo do jogo, a fascinação que exerce, reside justamente no fato de que o jogo se assenhora do jogador" (p. 160).

O "espetáculo de andar pela areia" pode também ser um jogo, como o $n^{\circ} U m$ nos faz perceber. "Você às vezes olha na tua frente, você olha e vê uma imagem, uma coisa qualquer que você vai chegar". Nesse jogo os atores representam seus papéis, e assim o jogo tornase representação; mas o próprio jogo é o conjunto dos atores e espectadores. Segundo Gadamer (2011), isso significa, para os jogadores, que não irão simplesmente exercer seus papéis como em todo e qualquer jogo; antes, representam seus papéis diante de outros, eles os representam para o espectador. Neste caso, sua forma de participação no jogo já não é determinada pelo fato de serem totalmente absorvidos e se perderem nele, mas, por jogarem, representam seus papeis por referência e com vista ao conjunto do espetáculo no qual não eles, mas os espectadores é que devem ser totalmente absorvidos. É uma mudança total, que acontece ao jogo como jogo quando se torna espetáculo. Coloca o espectador no lugar do jogador (ator). É ele, e não o jogador (ator), para quem e em quem se joga (representa) o jogo (espetáculo). Naturalmente, como afirma Gadamer (2011), isso não quer dizer que também o jogador (ator) não possa experimentar o sentido do todo em que ele, representando, desempenha seu papel:

O espectador tem somente uma primazia
metódica: pelo fato de o jogo ser
realizado para ele, torna-se patente que
possui um conteúdo de sentido que deve
ser entendido, podendo por isso ser
separado do comportamento do jogador
(ator). No fundo, aqui se anula a
distinção entre jogador (ator) e
espectador. A exigência de se visar o
jogo mesmo, no seu conteúdo de
sentido, é igual para ambos. (Gadamer,
2011, p. 164)

Realmente, no "espetáculo de andar pela areia" anula-se a diferença entre jogador (ator) e espectador, ou seja, não sabemos quem é o ator e quem é o espectador, o papel que o $n^{\circ} \mathrm{Um}$ representa, e o que representa a "tal" da "imagem, uma coisa qualquer que você vai chegar". Interpretamos, então, que com a atividade na praia o $n^{\circ} \mathrm{Um}$ reencontra o "algo" melhor (Coelho Filho, 2007), também no jogo contemplativo com a "natureza humana": "Sempre tem alguma coisa para te motivar. Não 
é isso? Andar pela areia, areia. Não tem nada mais que te motive a andar pela areia? Apreciar". Não obstante, independentemente da natureza contemplada, a ida até a praia (ao Alto da Boa Vista, às Paineiras, ou mesmo até a academia de ginástica) para o "movimento" na "caminhada" e o reencontro do repouso (do "algo" melhor), não deixa de ser uma coragem, e o mundo contemplado é o cenário de uma vida de "herói". Tanto mais, como observa o $n^{\circ} U \mathrm{~m}$ : "você olha e vê uma imagem, uma coisa qualquer que você vai chegar". Como nos alerta Bachelard (2001), "feliz daquele que, de manhã, para iniciar sua jornada, tem sob os olhos não somente belas imagens, mas imagens fortes" (p. 58).

Enfim, brincar com "algo" que brinca com o jogador também exige que se assuma uma obrigação. Como diz Buytendijk (1977), "não existem formas autênticas de jogo sem ilusão e sem um esquema de autocompromissos aceitos" (p. 76). Essa "seriedade" do jogo não apenas se liga à alegria, mas "interioriza" a alegria, transformando-a em felicidade. O $n^{\circ} \mathrm{Um}$ é um apaixonado: "Rapaz, hoje isso aí eu não largo de jeito nenhum. Só aqui na academia eu vou para... A academia tem 25 anos; eu tenho 23 anos de academia". "A unidade de seriedade e felicidade é uma das características de qualquer paixão", acrescenta Buytendijk (1977). Essa unidade de "jogo e compromisso assumido" remonta inteiramente à imaginação.

\section{CONSIDERAÇÕES FINAIS}

Tendo em vista a análise e a interpretação dos dados empíricos coletados no presente "estudo de caso", isto é, do caso particular de adesão de um indivíduo à prática regular de atividades físico-esportivas, destacamos as seguintes conclusões: (1) a prática de atividades físico-esportivas pode estar associada a motivos que não são representados, isto é, a impulsos que permanecem obscuros; (2) o sujeito pratica regularmente atividades físico-esportivas porque com ela se sente mais consciente dos seus limites, da sua potência, da sua estética; (3) sua prática regular está associada à identificação com atividades físico-esportivas variadas; (4) o sujeito pratica-as regularmente porque associa essa prática a um remédio saudável, porque "mexer com o corpo é brincar com o corpo" (Gadamer, 2011); (5) considerando as grandes imagens do refúgio (repouso) (Bachelard, 2001), quais sejam, a casa, o ventre, a gruta, concluímos que o sujeito da pesquisa, na relação com a falibilidade do seu corpo (na "intimidade do conflito"), pratica regularmente atividades físico-esportivas porque com essa prática reencontra o repouso, o "afago materno", senão fica "com dor na consciência"; (6) como nos mostra Bachelard, os devaneios materiais mudam a dimensão de nossas potências; "dãonos as ilusões da onipotência. Essas ilusões são úteis, pois já são um encorajamento para atacar a matéria em seu âmago" (Bachelard, 2001, p. 20). No caso estudado, a matéria a ser atacada, o próprio corpo, é renovada com a prática da atividade físico-esportiva, o que nos leva a concluir que esta proporciona ao sujeito a alegria imaginada da não transformação, o repouso no "berço materno", a potência. Dito em outras palavras, 0 sujeito pratica regularmente atividades físico-esportivas porque as qualidades da imaginação o confortam, a ilusão o acolhe e o move.

Por fim, salientamos a importância das constatações do presente estudo. Essas constatações podem se apresentar como informações instigadoras para profissionais das áreas de Psicologia, Educação e Saúde, nos diferentes espaços/momentos em que o discurso sobre a adoção de comportamentos fisicamente ativos é elencado. Também o podem para os praticantes de atividades físico-esportivas, no sentido da consciência corporal (corpo como consciência), e para o sujeito que deseja fazer exercícios físicos, mas na prática não consegue adquirir o comportamento.

\section{REFERÊNCIAS}

Alves-Mazzotti, A. J. (2006). Usos e abusos dos estudos de caso. Cadernos de Pesquisa, 129, 637-651.

Bachelard, G. (2001). A terra e os devaneios da vontade (2a ed.). (M. E. Galvão, Trad.). São Paulo: Martins Fontes. (Original publicado em 1948).

Bardin, L. (1977). Análise de conteúdo. Lisboa: Edições 70.

Bhabha, H. K. (1998). O local da cultura. (M. Ávila, E. L. Lima Reis e G. R. Gonçalves, Trad.). Belo Horizonte: UFMG. (Original publicado em 1994).

Buytendijk, F. J. J. U. (1977). O jogo humano. In: H. G. Gadamer \& P. Vogler (Orgs.), Nova antropologia: o homem em sua existência biológica, social e cultural (pp. 63-87). São Paulo: Epu/Edusp. 
Castro, M. S., Miranda, M., Silva, N. L., Palma, A., \& Resende, H. G. (2009). Motivos de ingresso nos programas de exercícios físicos oferecidos pelo Serviço Social do Comércio - SESC - DF. Movimento, 15, 87-102.

Ciampa, A. da C. (2001). A estória do Severino e a história da Severina. São Paulo: Brasiliense.

Coelho Filho, C. A. de A. (2007). Metamorfose de um corpo andarilho: busca e reencontro do "algo" melhor. São Paulo: Casa do Psicólogo.

Costa, V. L. de M. (2000). Esportes de aventura e risco na montanha: um mergulho no imaginário. Rio de Janeiro: Manole.

Feitosa, C. (2002). Labirintos: corpo e memória nos textos autobiográficos de Nietzsche. In: D. Lins \& S. Gadelha (Orgs.), Nietzsche e Deleuze: que pode o corpo (pp. 49-66). Rio de Janeiro: Relume Dumará.

Foucault, M. (1985). História da sexualidade 3: o cuidado de si. (M. T. Costa Albuquerque, Trad.). Rio de Janeiro: Graal. (Original publicado em 1984).

Foucault, M. (1996). A ordem do discurso (3a ed.). (L. F. Almeida Sampaio, Trad.). São Paulo: Loyola. (Original publicado em 1971).

Freud, S. (1974). Sobre o narcisismo: uma introdução. In S. Freud (J. Salomão, Trad.), Edição standard brasileira das obras psicológicas completas de Sigmund Freud (Vol. 14, pp. 85-125). Rio de Janeiro: Imago. (Original publicado em 1914)

Gadamer, H. G. (2011). Verdade e método: traços fundamentais de uma hermenêutica filosófica (11a ed.). (F. P. Meurer, Trad.). Petrópolis: Vozes. (Original publicado em 1960)

Lacan, J. (1998). Escritos. (V. Ribeiro, Trad.). Rio de Janeiro: Zahar. (Original publicado em 1966).

Laplanche, J., \& Pontalis, J. B. (1970). Vocabulário da psicanálise. (P. Tamen, Trad.). São Paulo: Martins Fontes. (Original publicado em 1967).
Molina, J. P., \& Beltrán, V. J. (2007). Motor incompetence and performance ideology in physical education: the case of a student with intellectual disability. Motricidad. European Journal of Human Movemen, 19, 157-180.

Moretti, A. C., Almeida, V., Westphal, M. F., \& Bógus, C. M. (2009). Práticas corporais/atividade física e políticas públicas de promoção da saúde. Saúde e Sociedade, 18, 346-354.

Organización Panamericana de la Salud. (2006). Impulso panamericano en favor de una dieta saludable y actividad física. Recuperado em 31 de janeiro, de 2012, de http://www.paho.org/Spanish/DD/PIN/ps060228.h tm\#Top

Palma, A. (2009). Exercício físico e saúde; sedentarismo e doença: epidemia, causalidade e moralidade. Motriz, 15(1), 185-191.

Queiroz, R. da S., \& Otta, E. (2000). A beleza em foco: condicionantes culturais e psicobiológicos na definição da estética corporal. In: R. da S. Queiroz (Org.), O corpo do brasileiro: estudos de estética e beleza (pp. 13-66). São Paulo: Senac.

Roudinesco, E., \& Plon, M. (1998). Dicionário de psicanálise. (V. Ribeiro e L. Magalhães, Trad.). Rio de Janeiro: Zahar (Original publicado em 1997).

Santos, S. C., \& Knijnik, J. D. (2006). Motivos de adesão à prática de atividade física na vida adulta intermediária. Revista Mackenzie de Educação Física e Esporte, 5(1), 23-34.

Vago, T. M. (2009). Pensar a educação física na escola: para uma formação cultural da infância e da juventude. Cadernos de Formação RBCE, 1, 25-42.

Recebido em 23/08/2012 Aceito em 04/06/2013

Carlos Alberto de Andrade Coelho Filho: doutor em Psicologia Social pela Universidade do Estado do Rio de Janeiro, professor adjunto da Faculdade de Educação Física e Desportos da Universidade Federal de Juiz de Fora, Brasil.

Regina Glória Nunes Andrade: doutora em Comunicação pela Universidade Federal do Rio de Janeiro, com pósdoutorado nas Universidades Paris V-René Descartes, Federal da Bahia e Federal Fluminense, professora titular do Instituto de Psicologia da Universidade do Estado do Rio de Janeiro, Brasil. 